\title{
Antarctic Summer Sea Ice Trend in the Context of High-Latitude Atmospheric Circulation Changes ${ }^{\circ}$
}

\author{
LEJIANG YU \\ State Oceanic Administration Key Laboratory for Polar Science, Polar Research Institute of China, \\ Shanghai, China, and Department of Geography, Environment and Spatial Sciences, \\ Michigan State University, East Lansing, Michigan \\ SHIYUAN ZHONG \\ Department of Geography, Environment and Spatial Sciences, Michigan \\ State University, East Lansing, Michigan \\ MINGYU ZHOU \\ State Oceanic Administration Key Laboratory for Polar Science, Polar Research Institute of China, \\ Shanghai, and National Marine Environment Prediction Center, Beijing, China
}

\section{Bo SUN}

State Oceanic Administration Key Laboratory for Polar Science, Polar Research Institute of China, Shanghai, China

DONALD H. LENSCHOW

National Center for Atmospheric Research, Boulder, Colorado

(Manuscript received 30 October 2017, in final form 1 March 2018)

\begin{abstract}
The potential mechanisms underlying the observed increasing trend in Antarctic summertime sea ice cover for the 1979-2017 period have been investigated using a relatively novel method called the selforganizing map (SOM). Among the nine nodes generated to explain the variability of Antarctic sea ice cover, two (nodes 3 and 7) exhibit a statistically significant linear trend in the time series of the frequency of the SOM pattern occurrence that together explain $40 \%$ of the total trend in the sea ice cover. These two nodes have completely opposite spatial patterns and directions of trend and are associated with different atmospheric circulation patterns. Node 3, which represents an increase in sea ice over the Weddell Sea and the eastern Ross Sea and a decrease over the other coastal seas of West Antarctica, appears to be related to the positive phase of the southern annular mode (SAM) linked with the La Niña pattern of sea surface temperature (SST) over the tropical Pacific Ocean. The opposite spatial pattern and trend represented by node 7 is associated with a wave train originating over northern Australia. The anomalous wind field, surface downward longwave radiation, and surface air temperature generated by these circulation patterns are consistent with the spatial pattern and overall trends in the Antarctic sea ice cover.
\end{abstract}

Supplemental information related to this paper is available at the Journals Online website: https://doi.org/10.1175/JCLI-D-170739.s1.

Corresponding author: Dr. Lejiang Yu, yulejiang@sina.com.cn

\section{Introduction}

Since the 1970s, Antarctic sea ice extent has displayed an overall increasing trend (Comiso and Nishio 2008; Parkinson and Cavalieri 2012; Holland 2014; Hobbs et al. 2016). Unlike the Arctic where sea ice has been

DOI: $10.1175 /$ JCLI-D-17-0739.1

(C) 2018 American Meteorological Society. For information regarding reuse of this content and general copyright information, consult the AMS Copyright Policy (www.ametsoc.org/PUBSReuseLicenses). 
on a downward trend consistently across the region, the Antarctic sea ice trends show regional differences, with an upward trend in the Weddell Sea, southern Pacific Ocean, and Ross Sea and downward trend in a portion of the southern Indian Ocean, Amundsen Sea, and Bellingshausen Sea (Turner et al. 2009; Parkinson and Cavalieri 2012).

Several studies have proposed different explanations for the nonuniformity in Antarctic sea ice changes. Some studies related the Antarctic sea ice change to a stronger Amundsen Sea low, which is attributable to both anthropogenic and natural factors, including stratospheric ozone depletion (Turner et al. 2009), Antarctic atmospheric intrinsic variability (Turner et al. 2016), and the sea surface temperature variations in the tropical Pacific (Clem and Fogt 2015). Recent research attributed the complex distribution of Antarctic sea ice trend to the Atlantic multidecadal oscillation (AMO) ( $\mathrm{Li}$ et al. 2014; Simpkins et al. 2014; Li et al. 2015a,b), the Pacific decadal oscillation (PDO) (Yu et al. 2017), and the more extended interdecadal Pacific oscillation (IPO) (Meehl et al. 2016; Purich et al. 2016). Sigmond and Fyfe (2014) considered greenhouse gas forcing as the major contribution to Antarctic sea ice change. Another proposed explanation is that the surface freshwater increase from the Antarctic ice sheet loss and subsurface ice shelf melt and increased snowfall reduce the upward ocean heat transport and thus sea surface temperature (SST), leading to the sea ice expansion (Liu and Curry 2010; Bintanja et al. 2013), although there are conflicting results on the role of surface freshening on sea ice trends (Swart and Fyfe 2013; Pauling et al. 2016; Haumann et al. 2016).

Although previous research has provided a variety of explanations for the overall increase in Antarctic sea ice, the answer remains far from clear. More studies are needed to distinguish anthropogenic from natural and local from remote contributions to Antarctic sea ice change. Although the trend in Antarctic sea ice in summer (December-February) is the smallest among the four seasons (Holland 2014), a small increase in summer sea ice could mean relatively large fractional change as a result of the high seasonality of Antarctica sea ice cover with minimum cover in summer. In addition, sea ice anomalies in summer have a direct impact on human activities in Antarctica that occur primarily during the summer season. In this study, we employed a statistical method called the selforganizing map (SOM) (Kohonen 2001) to investigate summertime Antarctic sea ice change caused by the natural variability, including both local and remote factors.
TABLE 1. The 38-yr average of spatial correlations between the seasonal Antarctic sea ice concentration and the corresponding SOM pattern for each year.

\begin{tabular}{lcccccccc}
\hline SOM grid & $2 \times 2$ & $2 \times 3$ & $2 \times 4$ & $3 \times 3$ & $3 \times 4$ & $3 \times 5$ & $4 \times 4$ & $4 \times 5$ \\
\hline $\begin{array}{c}\text { Correlation } \\
\text { coef }\end{array}$ & 0.47 & 0.46 & 0.48 & 0.54 & 0.55 & 0.58 & 0.58 & 0.60 \\
\hline
\end{tabular}

\section{Data and methods}

We analyzed the monthly sea ice concentration data from the National Snow and Ice Data Center (NSIDC; http://nsidc.org/data/NSIDC-0051) (Peng et al. 2013) using the National Aeronautics and Space Administration (NASA) Team (NT) algorithm (Cavalieri et al. 1996). The NSIDC dataset uses polar stereographic projection on a $25 \mathrm{~km} \times 25 \mathrm{~km}$ grid from December 1979 to February 2017. Sea ice concentration is defined as the percentage covered with ice in a grid cell. Although there are some limitations on the accuracy of the sea ice data, because of uncertainties in snow and surface flooding (Comiso and Steffen 2001) and land contamination and weather effects (Cavalieri et al. 1999), this widely utilized product can meet the requirements for understanding the interannual variability and trend of sea ice in the Antarctic oceans (i.e., Southern Ocean).

To explain the variability of Antarctic sea ice concentration, we employed the atmospheric variables derived from the European Center for Medium-Range Weather Forecasts (ECMWF) interim reanalysis (ERAInterim; Dee et al. 2011) for the 1979-2017 period and SST from the Hadley Centre Sea Ice and Sea Surface Temperature dataset (HadISST; http://www.metoffice. gov.uk/hadobs/hadisst/) from 1870 to the present (Rayner et al. 2003). Both datasets are on $1^{\circ} \times 1^{\circ}$ latitudelongitude grid.

The SOM technique was utilized to categorize anomalous sea ice concentration in an equal area grid south of $50^{\circ} \mathrm{S}$ for austral summer defined as December, January, and February (DJF). There are a total of 38 austral summers from December 1979 to February 2017 and the anomaly for each summer is calculated by subtracting the climatology (average of the 38 summers) from the average of that summer. Based on a neural network algorithm, the SOM technique utilizes unsupervised learning to reduce dimensionality of complex data into a two-dimensional array composed of matrix of nodes. Each node in the array has a reference vector that displays a spatial pattern of the input data. The patterns of all nodes in the array represent the full continuum of states in the input data. The distance between any two nodes is a measure of the similarity of their patterns with smaller distance for stronger similarity. The SOM 
5

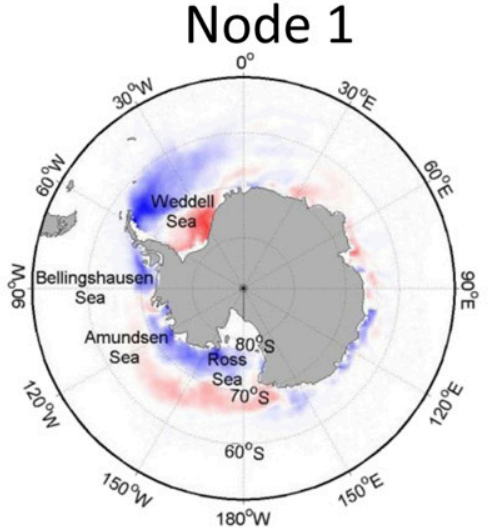

4

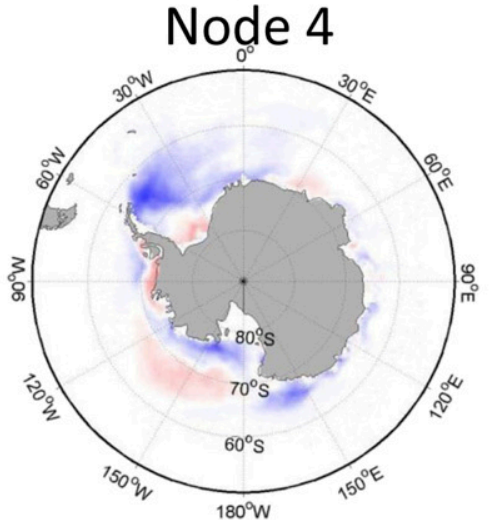

6

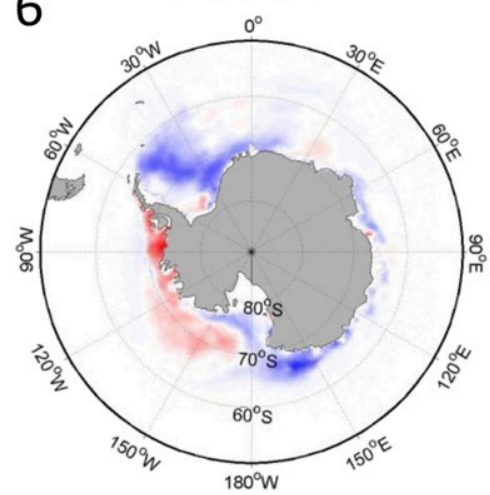

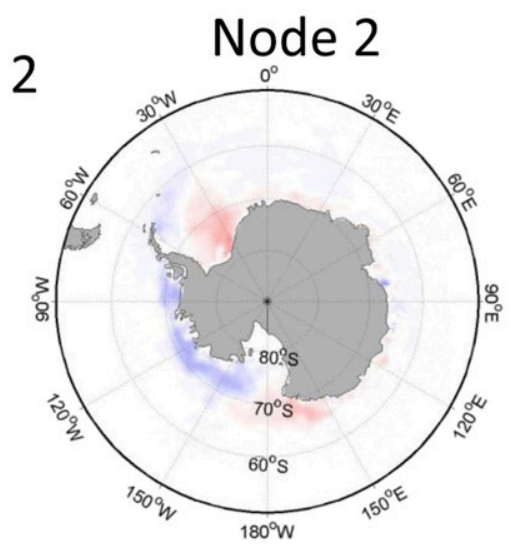

4

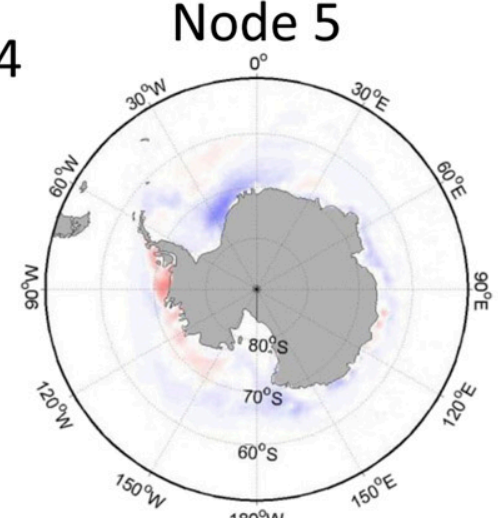

Node 8

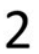

2

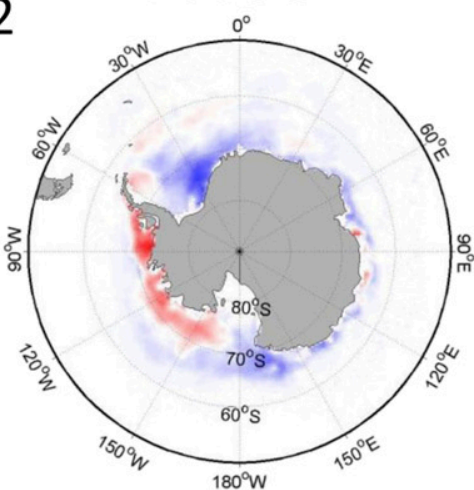

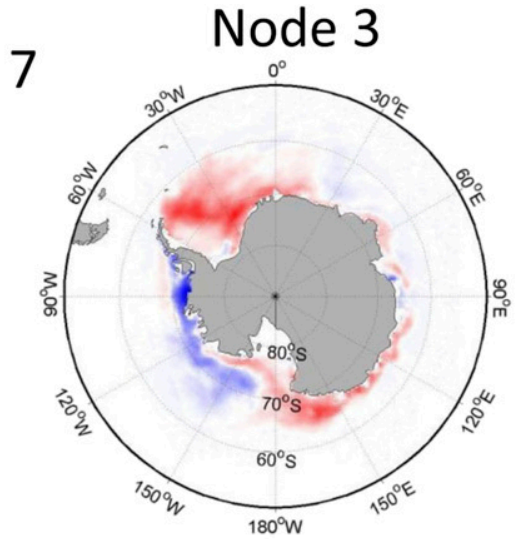

4

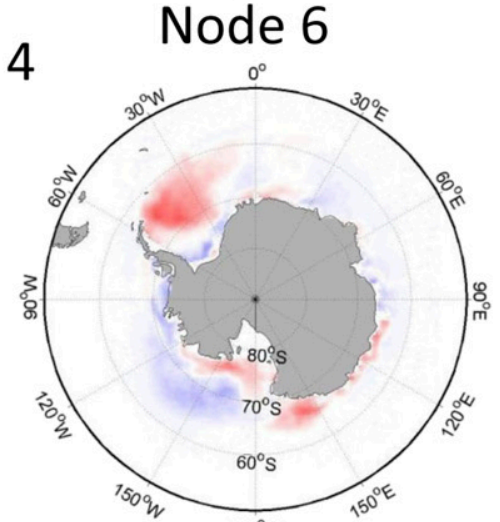

4

Node 9

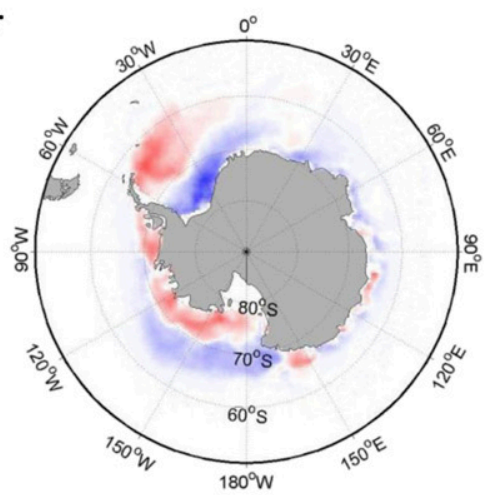

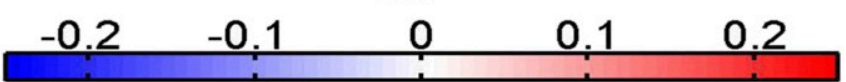

FIG. 1. The SOM patterns of the austral summer (DJF) sea ice concentration for a $3 \times 3$ grid for the period December 1979 through February 2017. The number at the top-left corner of each panel indicates the count of the node.

method has several advantages over other commonly used dimension reduction or clustering methods such as fuzzy $C$-means or $K$-means clustering or principal component analysis (PCA) (Reusch et al. 2005). By using a topological two-dimensional map, SOM extracts more effectively the continuum of patterns from an input dataset. SOM requires neither a priori assumptions about the distribution of the data (Hewitson and Crane
2002) nor orthogonality and linearity. As a result, SOM can generate more objectively and realistically the main patterns of input data compared to traditional hierarchical clustering methods. More details on the SOM method can be found in Kohonen (2001). In the past decade, SOM has been widely used in atmosphere and ocean sciences to obtain a continuum of atmospheric and oceanic patterns (Hewitson and Crane 2002; Leloup 


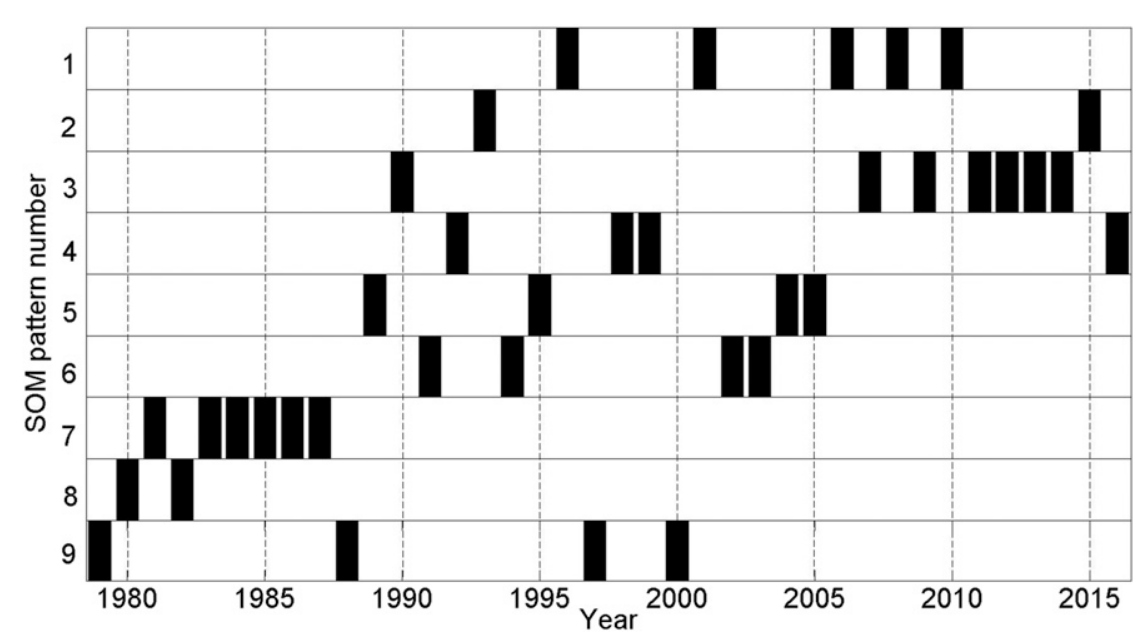

FIG. 2. Occurrence time series for each SOM pattern in Fig. 1 for the period December 1979 through February 1980. The year on the horizontal axis denotes the austral summer from December of that year to February of the next year.

et al. 2007; Johnson et al. 2008; Lee et al. 2011; Chu et al. 2012). For example, Johnson (2013) used SOM to examine the contributions of different ENSO flavors to the trend in the tropical Pacific sea surface temperature. The SOM technique was also employed to reveal the annual cycle of the Antarctic sea ice (Reusch and Alley 2007).

\section{Results}

While performing a SOM analysis, it is critical to determine the number of nodes. The requirements for a proper number of SOM nodes or SOM grids are that the number should be large enough to reflect the variability of data, which in this case is summertime Antarctic sea ice, and small enough to capture conveniently the variability (Johnson 2013; Lee and Feldstein 2013). To determine the proper number of SOM nodes, we calculated the spatial correlation between each sea ice field and its best-matching SOM pattern (Table 1). From the $3 \times 3$ to $4 \times 5$ grids, the mean spatial correlation between the summer season Antarctic sea ice concentrations and the corresponding SOM patterns for each year varies steadily from 0.54 to 0.60 . The slow change also exists for the grid number of less than 9. In contrast, an abrupt change occurs from 0.48 for the $2 \times 4$ grid to 0.54 for the $3 \times 3$ grid. Thus, a $3 \times 3$ grid is chosen for this study.
The spatial patterns for the nine nodes are shown in Fig. 1. Anomalous austral summertime sea ice shows considerably larger variability on the coastal sea of West Antarctica than that of East Antarctica, especially on the Weddell Sea, Bellingshausen Sea, Amundsen Sea, and Ross Sea. Node 1 shows that in the Weddell Sea there is a negative sea ice concentration anomaly in the outer sea and a positive anomaly in the inner sea, and vice versa for the Amundsen and Ross Seas. Node 9 shows an opposite phase to node 1 . Nodes 4 and 6 are in transition between nodes 1 and 9. The other five nodes exhibit a tripole distribution of sea ice concentration, in which the sea ice on Weddell Sea and western Ross Sea has opposite variability to that in eastern Ross, Amundsen, and Bellingshausen Seas. Among the five nodes, nodes 3 and 7 show greater variability, but their phases are opposite.

To determine the frequency of occurrence of each node, we assign each DJF sea ice concentration to the best-matching SOM pattern on the basis of minimum Euclidean distance. The number at the top-left corner of the panel for each node in Fig. 1, which indicates the count of occurrence of the pattern depicted by that node during the 38 summer seasons, show that node 3 has the highest count ( 7 summers), followed by node 7 (6 summers), and nodes 2 and 8 have the smallest count (2 summers each). To determine how much the nine

TABLE 2. Trends in the frequency of occurrence for each of nine SOM nodes. Asterisks indicate trends that are significant at or above the $95 \%$ confidence level based on the two-tailed Student's $t$ test.

\begin{tabular}{|c|c|c|c|c|c|c|c|c|c|}
\hline & Node 1 & Node 2 & Node 3 & Node 4 & Node 5 & Node 6 & Node 7 & Node 8 & Node 9 \\
\hline Trend $\left(\mathrm{yr}^{-1}\right)$ & 0.0073 & 0.0028 & $0.0161 *$ & 0.0033 & 0.0007 & 0.0000 & $-0.0173^{*}$ & -0.0072 & -0.0057 \\
\hline
\end{tabular}


SOM patterns resemble the anomalous austral summertime sea ice fields, we calculated the spatial correlation between each sea ice field and its best-matching SOM pattern. The mean spatial correlation is 0.54 , indicating a close resemblance between the nine SOM patterns and seasonal sea ice pattern for each austral summer. The anomalous sea ice concentration maps for the 38 austral summers are given in the figures of the supplemental material to demonstrate how well the SOM categorizes sea ice concentration during each summer.

Next we calculate trends in the frequency of occurrence of SOM patterns and their contribution to the trends in austral summertime sea ice concentration. Figure 2 exhibits occurrence time series for each of the nine SOM patterns and the linear trends for each node are shown in Table 2. Nodes 7, 8, and 9 occurred exclusively before and up to 2000, whereas node 1 and 3 occurred predominantly after 2000. Among the nine nodes, only nodes 3 and 7 have statistically significant trends at above $95 \%$ level in their occurrences, with slopes of 0.0161 and $-0.0173 \mathrm{yr}^{-1}$, respectively (Table 2 ). The significantly decreasing (increasing) trend for node 7 (node 3) represent a transition from less (more) sea ice cover in the Weddell Sea and Ross Sea (Amundsen Sea and Bellingshausen Sea) to the opposite pattern. Trends in the occurrence of other nodes are statistically insignificant.

To determine how the nine SOM pattern occurrence trends contribute to Antarctic sea ice concentration trends, we calculate the SOM-derived trend using the methods from Johnson (2013). The contribution of each SOM pattern to the trends in Antarctic sea ice concentration is calculated by the product of each SOM pattern (Fig. 1) and the frequency trend of occurrence of each SOM pattern (Table 2). The sum of these contributions denotes the Antarctic sea ice trends explained by the SOM patterns. Residual trends are calculated by subtracting SOM-explained trends from the total trends. Figure 3 shows the total and SOM-derived sea ice concentration trends. The total trend in Antarctic sea ice concentration is upward over the Weddell Sea, eastern Ross Sea, and the southern Indian Ocean and downward over the Bellingshausen Sea and Amundsen Sea, with an overall increasing sea ice cover in Antarctica (Fig. 3a). The trend related to all nine nodes explains up to $50 \%$ of total trends (Fig. 3b). Spatial patterns of trends in sea ice concentration related to each node are shown in Fig. 4. The major contributions to the total trend are from node 3 , which explains $20.3 \%$ of the total trends, and node 7 , which contributes $19.6 \%$, with all the other nodes together accounting for less than $10 \%$ of the total trend. The residual trend (Fig. 3c), which is the difference
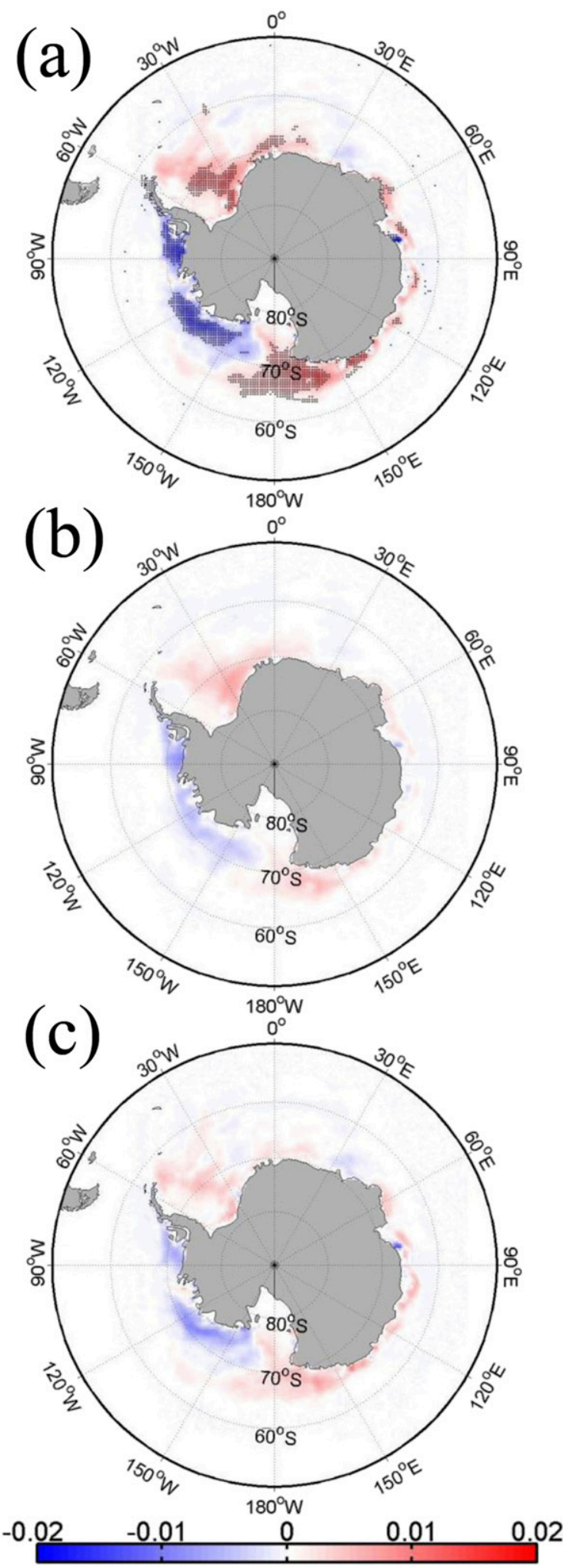

FIG. 3. (a) Total, (b) SOM-explained, and (c) residual DJF sea ice concentration trends $\left(\mathrm{yr}^{-1}\right)$. Dotted areas in (a) indicate above $95 \%$ confidence level based on the two-tailed Student's $t$ test. 

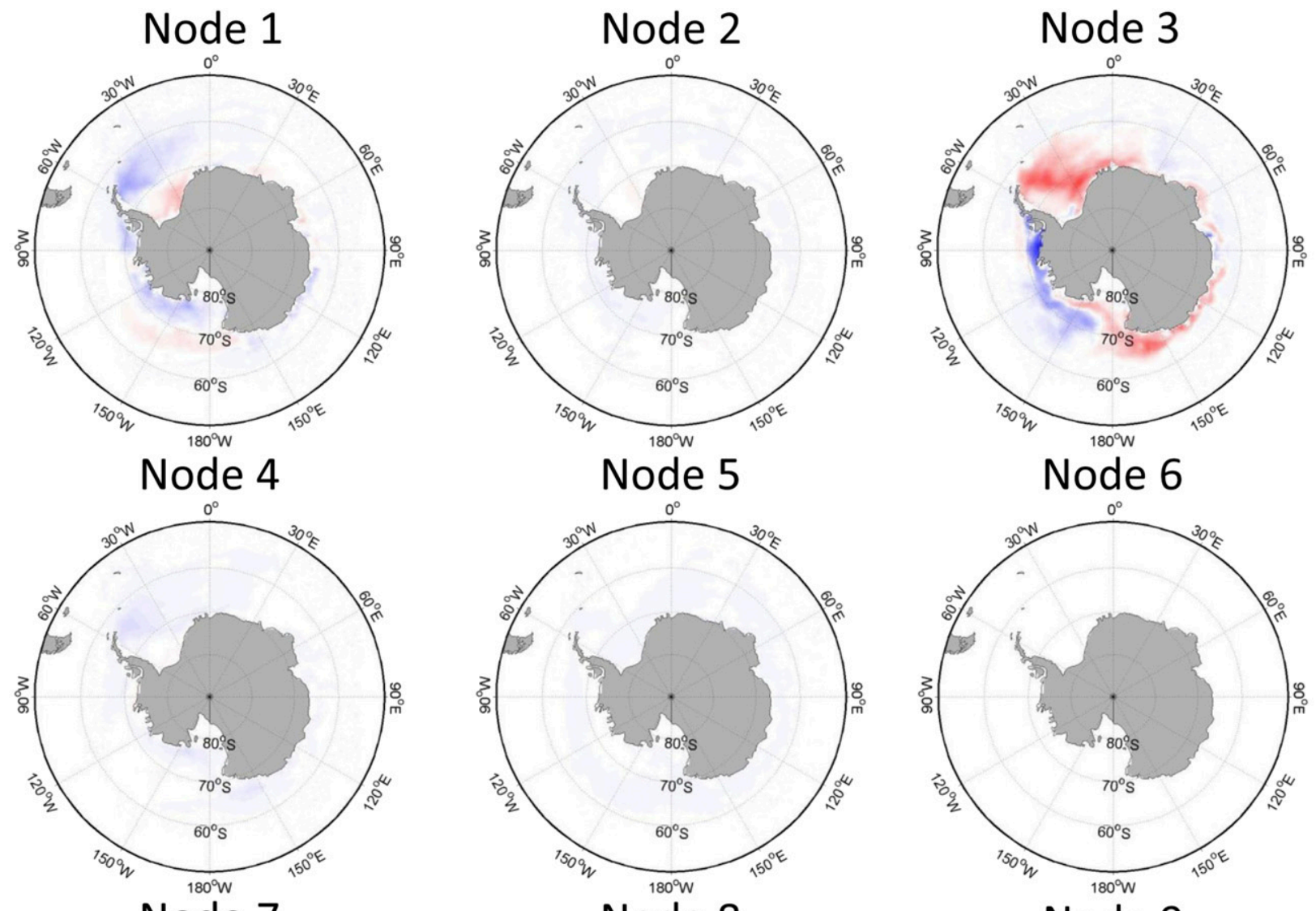

Node 7
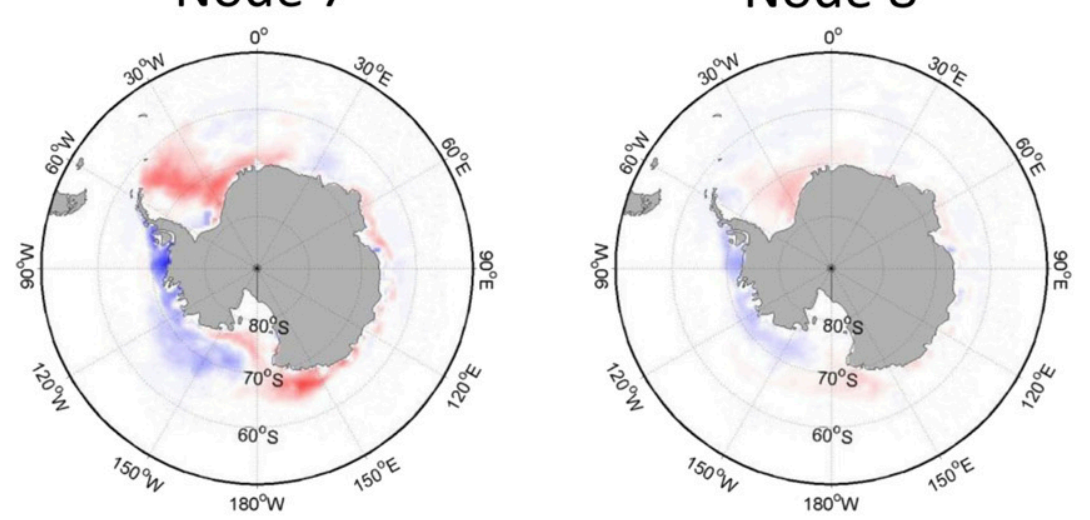

Node 9
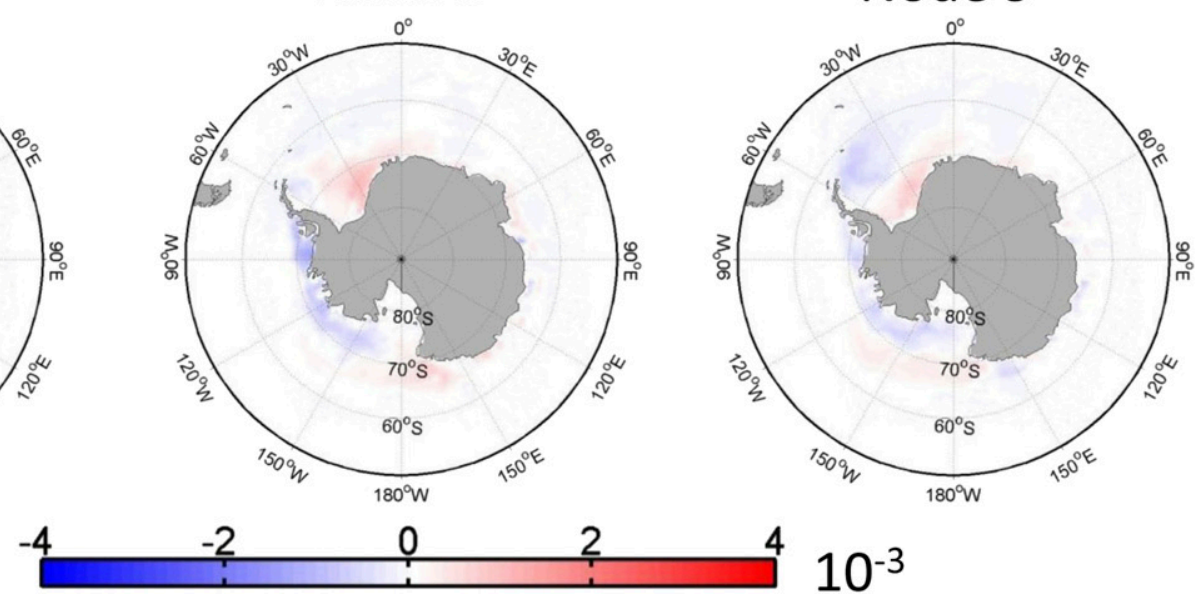

FIG. 4. Trends in sea ice concentration explained by each SOM pattern $\left(\mathrm{yr}^{-1}\right)$.

between the total and SOM-derived trends, has a spatial pattern similar to that of the total trend.

To put the spatial distribution of the Antarctic sea ice concentration in the context of large-scale atmospheric circulations, we examine composites of anomalous SST along with several atmospheric variables, including 500-hPa geopotential heights, mean sea level pressure (MSLP), 850-hPa winds, surface-750-hPa specific humidity, surface downward longwave radiation, and surface air temperature, over the years when node 3 occurred and years when node 7 occurred, respectively, and the composite results are shown in Figs. 5, 6, and 7.

During the occurrence years of node 3 , the anomalous 500-hPa geopotential height composite field (Fig. 5c) at southern mid-to-high latitudes resembles a positive 
(a)

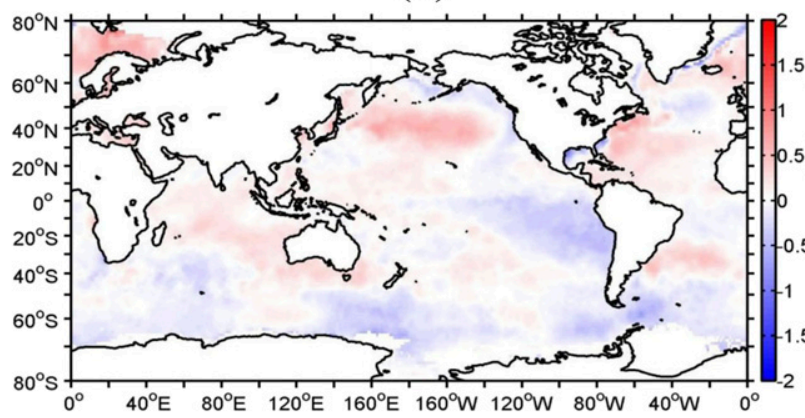

(c)

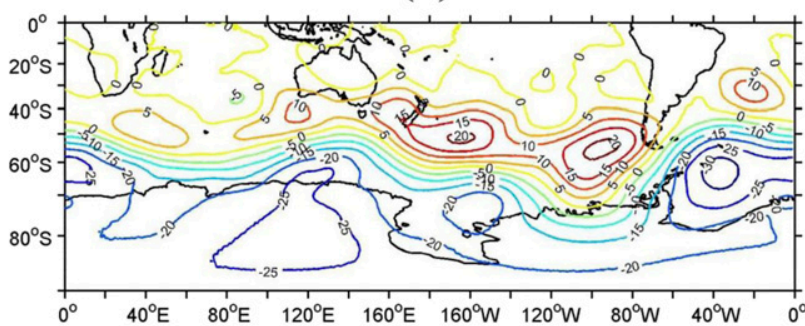

(e)

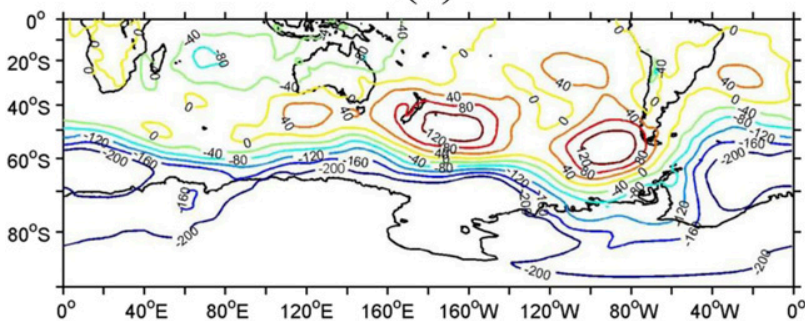

(b)

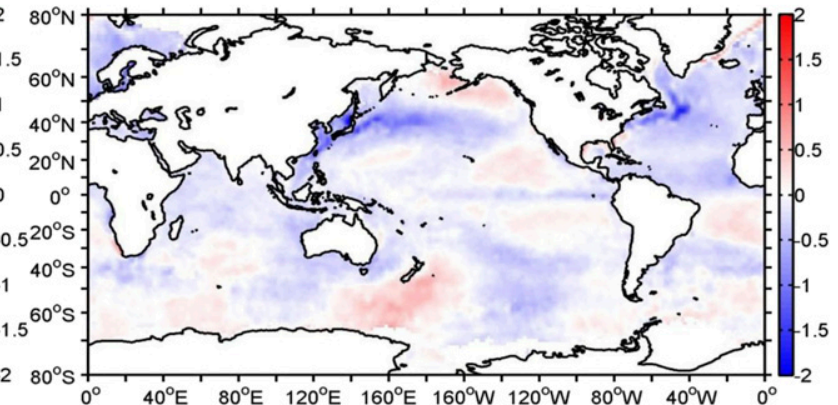

(d)

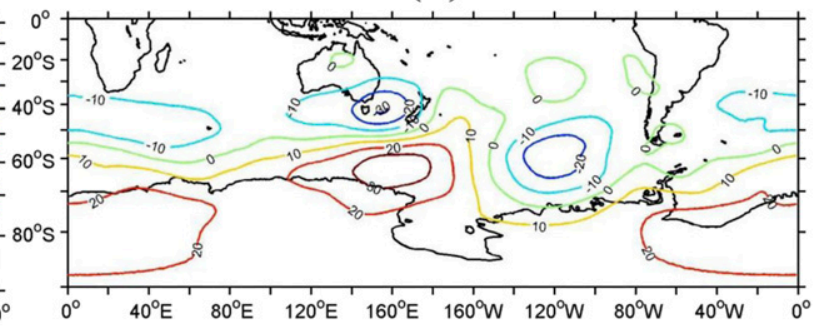

(f)

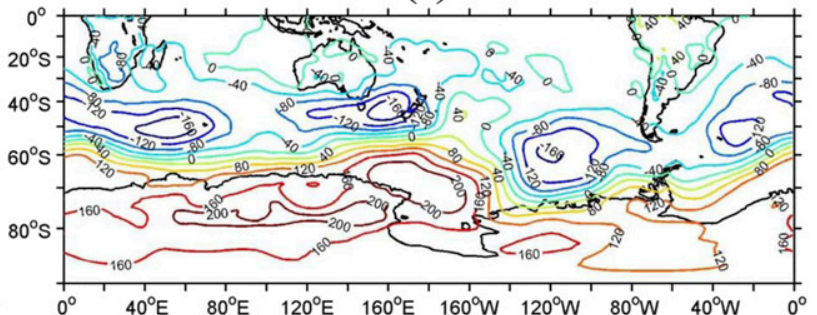

FIG. 5. Composites of anomalous (a),(b) SST $\left({ }^{\circ} \mathrm{C}\right),(\mathrm{c}),(\mathrm{d})$ 500-hPa geopotential height (gpm), and (e),(f) MSLP (Pa) for nodes (left) 3 and (right) 7 .

phase of the southern annular mode (SAM), which is related to a La Niña pattern of SST over the tropical Pacific Ocean (Fig. 5a) (L'Heureux and Thompson 2006; Fogt et al. 2011; Ciasto et al. 2015) and influenced by other factors including increasing greenhouse gases (which act all year round) and stratospheric ozone depletion (which influences SAM trends during austral summer) (Arblaster and Meehl 2006; Son et al. 2010; Polvani et al. 2011). Anomalous MSLP also shows a similar spatial structure, indicating a barotropic response to anomalous SST in the tropical Pacific Ocean (Fig. 5e). The lowest geopotential height center occurs over the Weddell Sea, and there are two other negative anomaly centers over the Ross Sea and Wilkes Land. The negative geopotential height anomalies over the Weddell Sea produce an anomalous cyclonic circulation and anomalous southerly winds, thus leading to increased cold air intrusion and sea ice concentration (Fig. 6a). Meanwhile the stronger katabatic winds result in a larger sea ice cover on the Weddell Sea. The decreased water vapor in the lower troposphere over the Weddell Sea (Fig. 7a) reduces downward longwave radiation (Fig. 7c), thus producing colder surface air temperature (Fig. 7e) and positive sea ice anomalies there. The larger positive center occurring over the southeastern Pacific Ocean (Fig. 5c) induces anomalous northwesterly winds (Fig. 6a), which transports warm and moist air over the Amundsen and eastern Ross Seas, thus increasing downward longwave radiation and surface air temperature (Figs. 7a,c,e) and decreasing sea ice concentration (Fig. 1). The reduced sea ice in the Bellingshausen Sea is related to the polynya caused by stronger coastal katabatic winds, which is accompanied by a slight increase in sea ice north of it (Gallée, 1997). The increased sea ice in the western Ross Sea results from the higher ice production also caused by stronger katabatic winds (Gallée, 1997). The wind convergence over the southwestern Pacific Ocean (Fig. 6a) also favors 
(a)

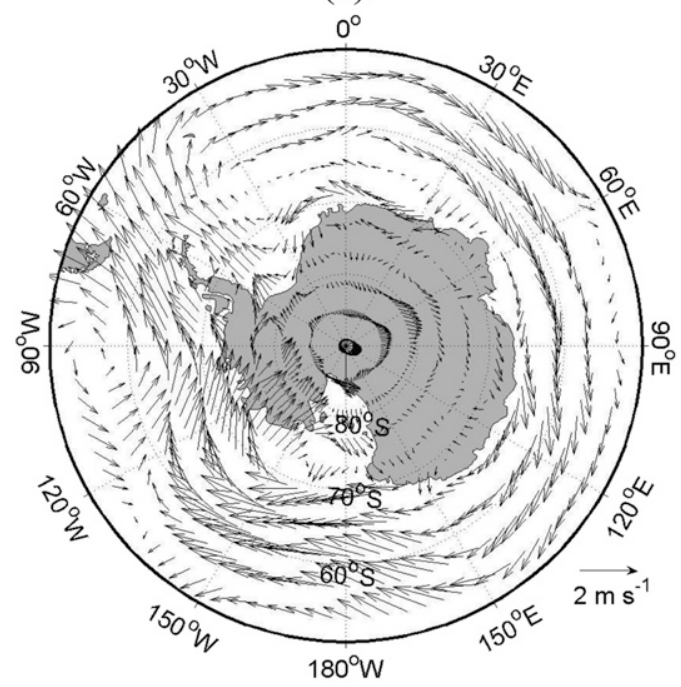

(b)

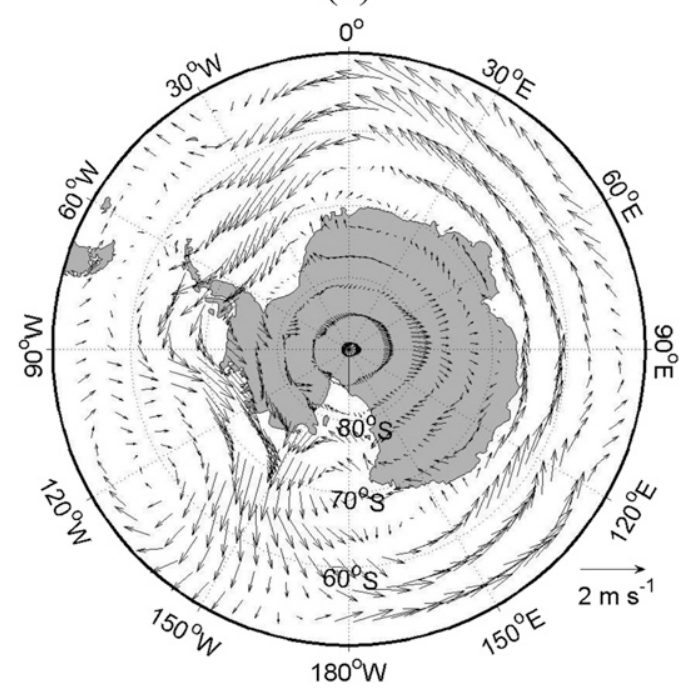

FIG. 6. Composites of anomalous 850-hPa winds for nodes (a) 3 and (b) 7.

increasing sea ice on the western Ross Sea (Fig. 1). The increasing sea ice on the southwestern Pacific and southern Indian Ocean (Fig. 1) is associated with decreasing specific humidity, downward longwave radiation, and surface air temperature (Figs. 7a,c,e).

In contrast, the anomalous $500-\mathrm{hPa}$ geopotential height field for node 7 shows a wave train generated over northern Australia that produces strong geopotential height anomalies over the southern Pacific Ocean and the Antarctic continent (Fig. 5d). The wave train resembles the regression map of $500-\mathrm{hPa}$ geopotential height onto El Niño-Southern Oscillation (ENSO) and the Drake Passage Rossby wave (DPR) (Kohyama and Hartmann 2016). The wave train also is evident in the anomalous MSLP map (Fig. 5f). The sign of the geopotential height anomalies corresponds to that of the SST anomalies (Fig. 5b), suggesting that they interact over the Southern Ocean. The negative geopotential height anomalies over the southeastern Pacific Ocean generate anomalous northeasterly winds (Fig. 6b), which transport cold air associated with cold SST to the Amundsen Sea and increase the sea ice concentration (Fig. 1). The increased sea ice on the Bellingshausen Sea (Fig. 1) is related to sea ice convergence caused by anomalous northeasterly winds and decreased temperature resulting from reduced downward longwave radiation (Fig. 7d). The anomalous warm and moist northeasterly winds (Figs. 6b and $7 b$ ) induce positive geopotential height anomalies over the Weddell Sea (Fig. 5d) that enhance downward longwave radiation and surface air temperature (Figs. 7d and 7f, respectively), and thus decrease the sea ice cover there (Fig. 1). Positive sea ice anomalies on the eastern Ross Sea are related to stronger katabatic winds from the Ross Ice Shelf. The positive SST and northerly wind anomalies increase surface air temperature over the southern Indian Ocean (Fig. 6b). Stronger downward longwave radiation (Fig. 7d) also plays an important role in the increased temperature and decreased sea ice.

To further confirm the link between the variability of SST and atmospheric variables and the Antarctic sea ice trend in Fig. 1, we project the sea ice concentration anomalies onto the node 3 and 7 patterns to obtain seasonal time series associated with the sea ice anomaly patterns and make regression maps of seasonal anomalies of atmospheric variables and SST onto the seasonal time series. The results are shown in Fig. 8. The regression map for node 3 is nearly a mirror image to that of node 7 , which is not surprising considering that the spatial patterns of node 3 and node 7 are close to a mirror image (Fig. 1). In comparison, the composite results shown above are asymmetric, suggesting that different processes might be involved in the two SOM states, which is highly likely because there have been considerable changes in the carbon dioxide and ozone concentrations in the past three decades that could influence how the summer Antarctic sea ice changed in the earlier and later parts of the study period (Hobbs et al. 2016).

The anomalous positive phase of the SAM linked with the anomalous SST pattern in the tropical Pacific Ocean and the wave train originating over northern Australia account for the opposite pattern of Antarctic sea ice concentration for nodes 3 and 7. The positive trend in the occurrence time series for node 3 and negative trend 

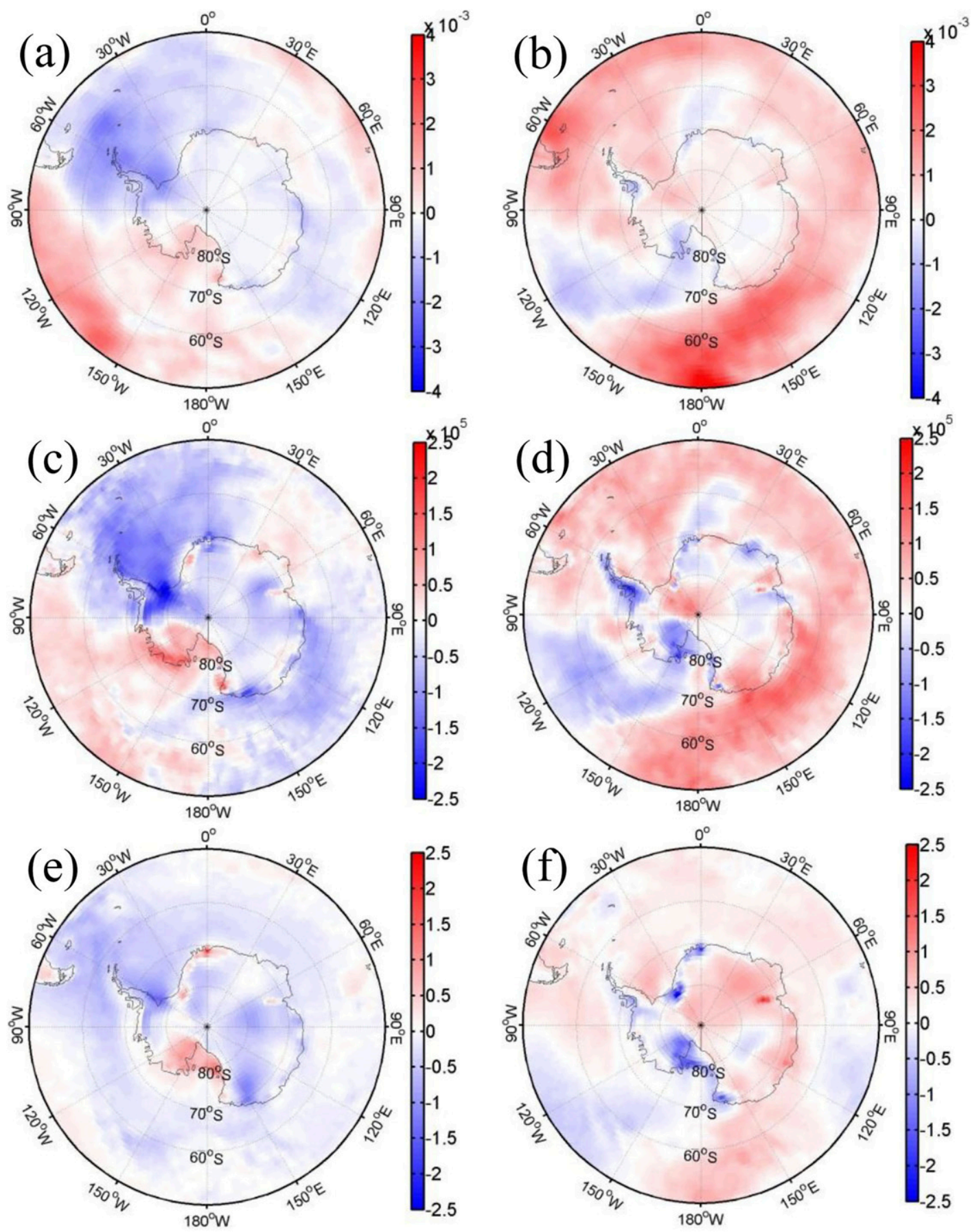

FIG. 7. Composites of (a),(b) surface-750-hPa specific humidity $\left(\mathrm{kg} \mathrm{kg}^{-1}\right)$, (c),(d) summer accumulated surface downward longwave radiation $\left(\mathrm{W} \mathrm{m}^{-2}\right)$, and (e),(f) surface air temperature $\left({ }^{\circ} \mathrm{C}\right)$ for nodes (left) 3 and (right) 7.

in the occurrence time series for node 7 explain nearly $40 \%$ of the total trend in the sea ice concentration.

\section{Conclusions and discussion}

We apply the SOM method to the investigation of the mechanisms for the overall increase in Antarctic summertime sea ice cover for the period 1979-2017. We resolve the austral summertime sea ice fields into nine nodes. Among them, two (nodes 3 and 7) have linear trends in their occurrence time series that are statistically significant and together they explain $40 \%$ of the total trend. These two nodes are completely opposite in their trends (0.0161 and $-0.0173 \mathrm{yr}^{-1}$, respectively) 
(a)

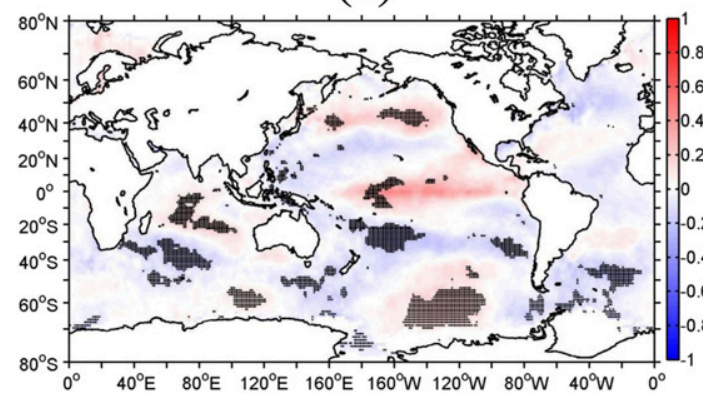

(c)

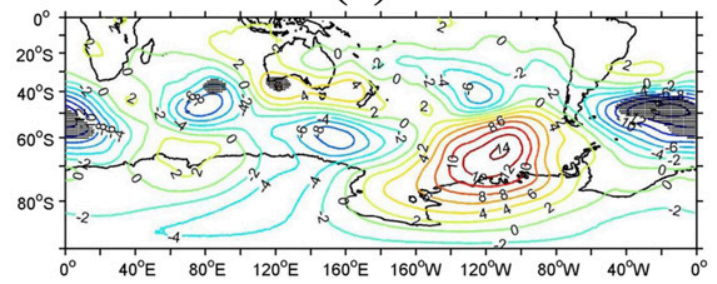

(b)

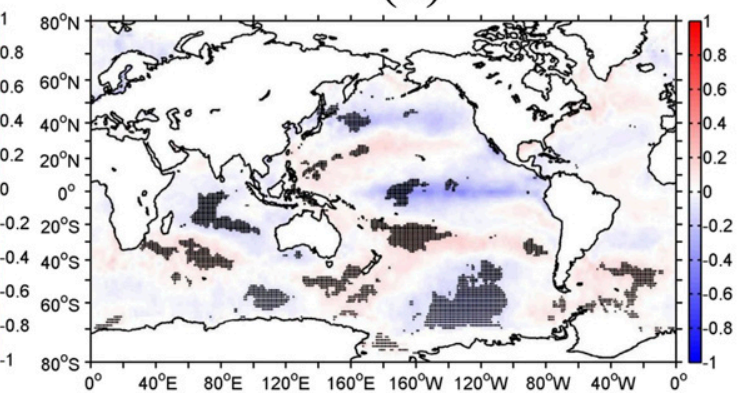

(d)

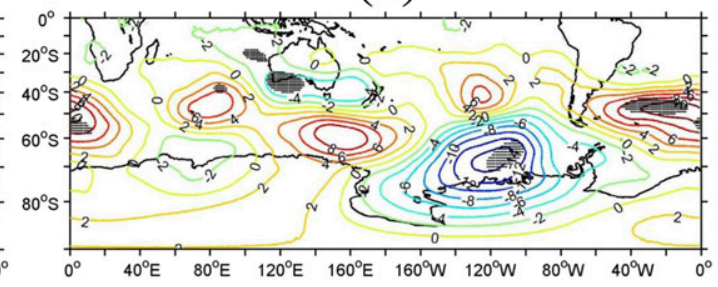

FIG. 8. Regression maps of seasonal anomalous (a),(b) SST and (c),(d) 500-hPa geopotential height onto the seasonal time series of nodes (left) 3 and (right) 7 . Dotted areas indicate regions with above $95 \%$ confidence level based on the two-tailed Student's $t$ test.

as well as their spatial patterns and together they represent a transition from the spatial distribution depicted by node 7 (characterized by anomalously low sea ice cover in the Weddell Sea and Ross Sea and anomalously high cover in the Amundsen Sea and Bellingshausen Sea in the earlier part of the December 1979-February 2017 study period) to the opposite pattern represented by node 3 during the latter part of the period. The opposite trends of sea ice cover in different Antarctic seas can be largely explained by two different modes of atmospheric circulations. Specifically, the positive phase of the SAM associated with a La Niña pattern of SST over the tropical Pacific Ocean (for node 3 ) and a wave train originating over northern Australia (for node 7) produce anomalous winds that transport warm moisture-laden air to some regions of the Antarctic seas but cold and dry air to other regions, affecting surface downward longwave radiation and surface air temperature, and thus sea ice cover. The other $10 \%$ of the total sea ice trends are explained by the other seven nodes.

Previous research has suggested that a stronger Amundsen Sea low leads to an overall increase in Antarctic sea ice. Node 7, which has a statistically significant decreasing trend of occurrence, appears to be associated with a weaker Amundsen Sea low, and node 3, which has a statistically significant increasing trend, does not favor a stronger Amundsen Sea low either (Figs. 5c,d). The absence of a strong Amundsen Sea low may be due to the seasonality of the Amundsen Sea low and its influence on sea ice. There is no significant negative trend in the 500-hPa geopotential height over the Amundsen and Bellingshausen Seas (Fig. 9a), where the austral summer Amundsen Sea low is usually located (Turner et al.2013). The spatial pattern of the trend in the $500-\mathrm{hPa}$ geopotential height anomalies resembles that for node 3 . (a)

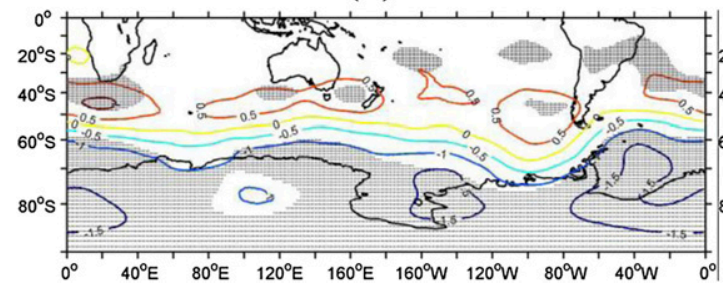

(b)

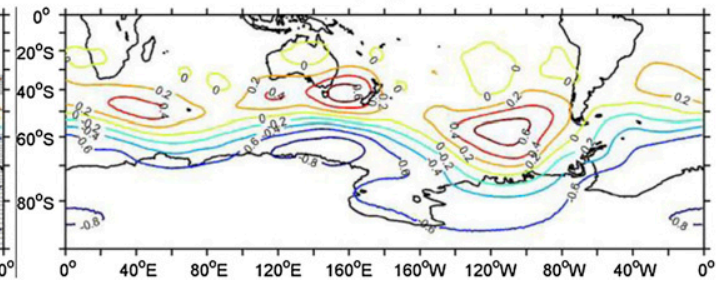

FIG. 9. (a) Total and (b) nodes 3- and 7-derived trends in austral summertime anomalous 500-hPa geopotential height anomalies (gpm) for the period December 1979 through February 2017. Dotted areas in (a) indicate regions with above $95 \%$ confidence level based on the two-tailed Student's $t$ test. 
We also calculated the contribution of the trends of nodes 3 and 7 to the trends in the anomalous 500-hPa geopotential heights (Fig. 9b). The grid-averaged contribution from the two nodes is $47 \%$, which is consistent with the large contribution of these two nodes to the Antarctic sea ice trend. The SST patterns for nodes 3 and 7 demonstrate that the IPO (PDO) (Meehl et al. 2016; Purich et al. 2016; Yu et al. 2017) and AMO (Li et al. 2014; Simpkins et al. 2014; Li et al. 2015a,b) also play an important role in Antarctic sea ice change (Figs. 5a,b). These large-scale circulation changes can also influence Antarctic precipitation and SST, leading to sea ice change.

Our results demonstrate that the opposite patterns (nodes 3 and 7) of summertime Antarctic sea ice trends may stem from different atmospheric processes, which may be associated with different background values and distributions in the SST over the Pacific and Atlantic Oceans (Figs. 5a,b) or the atmospheric greenhouse gas concentrations. The same forcing, when superimposed on different background, may lead to different results, or the same results may originate from different forcing. Although it is necessary to confirm these and other statistics-based results via process studies using numerical models, these results could be used to help improve the predictions of Antarctic sea ice concentrations on interannual-decadal time scales.

Acknowledgments. This study is sponsored by the Shanghai Pujiang Program (17PJ1409800).

\section{REFERENCES}

Arblaster, J. M., and G. A. Meehl, 2006: Contributions of external forcings to southern annular mode trends. J. Climate, 19, 28962905, https://doi.org/10.1175/JCLI3774.1.

Bintanja, R., G. J. van Oldenborgh, S. S. Drijfhout, B. Wouters, and C. A. Katsman, 2013: Important role for ocean warming and increased ice-shelf melt in Antarctic sea-ice expansion. Nat. Geosci., 6, 376-379, https://doi.org/10.1038/ngeo1767.

Cavalieri, D. J., C. L. Parkinson, P. Gloersen, and H. J. Zwally, 1996 (updated yearly): Sea ice concentrations from Nimbus-7 SMMR and DMSP SSM/I-SSMIS passive microwave data version 1. NASA National Snow and Ice Data Center Distributed Active Archive Center, https://doi.org/10.5067/ 8GQ8LZQVL0VL.

,,,--- J. C. Comiso, and H. J. Zwally, 1999: Deriving long-term time series of sea ice cover from satellite passivemicrowave multisensory data sets. J. Geophys. Res., 104, 15 803-15 814, https://doi.org/10.1029/1999JC900081.

Chu, J.-E., S. N. Hameed, and K.-J. Ha, 2012: Nonlinear intraseasonal phases of the East Asian summer monsoon: Extraction and analysis using self-organizing maps. J. Climate, $\mathbf{2 5}$ 6975-6988, https://doi.org/10.1175/JCLI-D-11-00512.1.

Ciasto, L. M., G. R. Simpkins, and M. H. England, 2015: Teleconnections between tropical Pacific SST anomalies and extratropical Southern Hemisphere climate. J. Climate, 28, 56-65, https://doi.org/10.1175/JCLI-D-14-00438.1.
Clem, K. R., and R. L. Fogt, 2015: South Pacific circulation changes and their connection to the tropics and regional Antarctic warming in austral spring, 1979-2012. J. Geophys. Res., 120, 2773-2792, https://doi.org/10.1002/2014JD022940.

Comiso, J. C., and K. Steffen, 2001: Studies of Antarctic sea ice concentrations from satellite data and their applications. J. Geophys. Res., 106, 31361-31385, https://doi.org/10.1029/ 2001JC000823.

—, and F. Nishio, 2008: Trends in the sea ice cover using enhanced and compatible AMSR-E, SSM/I, and SMMR data. J. Geophys. Res., 113, C02S07, https://doi.org/10.1029/ 2007JC004257.

Dee, D. P., and Coauthors, 2011: The ERA-Interim reanalysis: Configuration and performance of the data assimilation system. Quart. J. Roy. Meteor. Soc., 137, 553-597, https://doi.org/ 10.1002/qj.828.

Fogt, R. L., D. H. Bromwich, and K. M. Hines, 2011: Understanding the SAM influence on the South Pacific ENSO teleconnection. Climate Dyn., 36, 1555-1576, https://doi.org/ 10.1007/s00382-010-0905-0.

Gallée, H., 1997: Air-sea interactions over Terra Nova during winter simulation with a coupled atmosphere-polynya model. J. Geophys. Res., 102, 13 835-13 849, https://doi.org/10.1029/ 96JD03098.

Haumann, F. A., N. Gruber, M. Münnich, I. Frenger, and S. Kern, 2016: Sea-ice transport driving Southern Ocean salinity and its recent trends. Nature, 537, 89-92, https://doi.org/10.1038/ nature19101.

Hewitson, B. C., and R. G. Crane, 2002: Self-organizing maps: Applications to synoptic climatology. Climate Res., 22, 13-26, https://doi.org/10.3354/cr022013.

Hobbs, W. R., R. Massom, S. Stammerjohn, P. Reid, G. Williams, and W. Meier, 2016: A review of recent changes in Southern Ocean sea ice, their drivers and forcings. Global Planet. Change, 143, 228-250, https://doi.org/10.1016/j.gloplacha.2016.06.008.

Holland, P. R., 2014: The seasonality of Antarctic sea ice trends. Geophys. Res. Lett., 41, 4230-4237, https://doi.org/10.1002/ 2014GL060172.

Johnson, N. C., 2013: How many ENSO flavors can we distinguish? J. Climate, 26, 4816-4827, https://doi.org/10.1175/ JCLI-D-12-00649.1.

S. B. Feldstein, and B. Tremblay, 2008: The continuum of Northern Hemisphere teleconnection patterns and a description of the NAO shift with the use of self-organizing maps. J. Climate, 21, 6354-6371, https://doi.org/10.1175/ 2008JCLI2380.1.

Kohonen, T., 2001: Self-Organizing Maps. 3rd ed. Springer, 501 pp.

Kohyama, T., and D. L. Hartmann, 2016: Antarctic sea ice response to weather and climate modes of variability. J. Climate, 29, 721-741, https://doi.org/10.1175/JCLI-D-15-0301.1.

Lee, S., and S. B. Feldstein, 2013: Detecting ozone- and greenhouse gas-driven wind trends with observational data. Science, 339, 563-567, https://doi.org/10.1126/science.1225154.

— T. Gong, N. C. Johnson, S. B. Feldstein, and D. Polland, 2011: On the possible link between tropical convection and the Northern Hemisphere Arctic surface air temperature change between 1958 and 2001. J. Climate, 24, 4350-4367, https://doi.org/10.1175/2011JCLI4003.1.

Leloup, J., Z. Lachkar, J.-P. Boulanger, and S. Thiria, 2007: Detecting decadal changes in ENSO using neural networks. Climate Dyn., 28, 147-162, https://doi.org/10.1007/s00382-006-0173-1.

L'Heureux, M. L., and D. W. J. Thompson, 2006: Observed relationships between the El Niño-Southern Oscillation and the 
extratropical zonal-mean circulation. J. Climate, 19, 276-287, https://doi.org/10.1175/JCLI3617.1.

Li, X., D. M. Holland, E. P. Gerber, and C. Yoo, 2014: Impacts of the north and tropical Atlantic Ocean on the Antarctic Peninsula and sea ice. Nature, 505, 538-542, https://doi.org/ 10.1038/nature12945.

- E. P. Gerber, D. M. Holland, and C. Yoo, 2015a: A Rossby wave bridge from the tropical Atlantic to west Antarctica. J. Climate, 28, 2256-2273, https://doi.org/10.1175/JCLI-D-14-00450.1.

, D. M. Holland, E. P. Gerber, and C. Yoo, 2015b: Rossby waves mediate impacts of tropical oceans on West Antarctic atmospheric circulation. J. Climate, 28, 8151-8164, https:// doi.org/10.1175/JCLI-D-15-0113.1.

Liu, J., and J. Curry, 2010: Accelerated warming of the Southern Ocean and its impacts on the hydrological cycle and sea ice. Proc. Natl. Acad. Sci. USA, 107, 14 987-14 992, https://doi.org/ 10.1073/pnas.1003336107.

Meehl, G. A., J. M. Arblaster, C. Bitz, C. T. Y. Chung, and H. Teng, 2016: Antarctic sea ice expansion between 2000 and 2014 driven by tropical Pacific decadal climate variability. Nat. Geosci., 9, 590-595, https://doi.org/10.1038/ngeo2751.

Parkinson, C. L., and D. J. Cavalieri, 2012: Antarctic sea ice variability and trends, 1979-2010. Cryosphere, 6, 871-880, https:// doi.org/10.5194/tc-6-871-2012.

Pauling, A. G., C. M. Bitz, J. J. Smith, and P. J. Langhorne, 2016: The response of the Southern Ocean and Antarctic sea ice to freshwater from ice shelves in an Earth system model. J. Climate, 29, 1655-1672, https://doi.org/10.1175/JCLI-D-15-0501.1.

Peng, G., W. Meier, D. Scott, and M. Savoie, 2013: A long-term and reproducible passive microwave sea ice concentration data record for climate studies and monitoring. Earth Syst. Sci. Data, 5, 311-318, https://doi.org/10.5194/essd-5-311-2013.

Polvani, L. M., D. W. Waugh, G. J. P. Correa, and S.-W. Son, 2011: Stratospheric ozone depletion: The main driver of twentiethcentury atmospheric circulation changes in the Southern Hemisphere. J. Climate, 24, 795-812, https://doi.org/10.1175/ 2010JCLI3772.1.

Purich, A., and Coauthors, 2016: Tropical Pacific SST drivers of recent Antarctic sea ice trends. J. Climate, 29, 8931-8948, https://doi.org/10.1175/JCLI-D-16-0440.1.

Rayner, N. A., D. E. Parker, E. B. Horton, C. K. Folland, L. V. Alexander, D. P. Rowell, E. C. Kent, and A. Kaplan,
2003: Global analyses of sea surface temperature, sea ice, and night marine air temperature since the late nineteenth century. J. Geophys. Res., 108, 4407, https://doi.org/10.1029/ 2002JD002670.

Reusch, D. B., and R. B. Alley, 2007: Antarctic sea ice: A selforganizing map-based perspective. Ann. Glaciol., 46, 391-396, https://doi.org/10.3189/172756407782871549.

,-- , and B. C. Hewitson, 2005: Relative performance of selforganizing maps and principal component analysis in pattern extraction from synthetic climatological data. Polar Geogr., 29, 188-212, https://doi.org/10.1080/789610199.

Sigmond, M., and J. C. Fyfe, 2014: The Antarctic sea ice response to the ozone hole in climate models. J. Climate, 27, 1336-1342, https://doi.org/10.1175/JCLI-D-13-00590.1.

Simpkins, G. R., S. McGregor, A. S. Taschetto, L. M. Ciasto, and M. H. England, 2014: Tropical connections to climatic change in the extratropical Southern Hemisphere: The role of Atlantic SST trends. J. Climate, 27, 4923-4936, https://doi.org/ 10.1175/JCLI-D-13-00615.1.

Son, S.-W., and Coauthors, 2010: Impact of stratospheric ozone on Southern Hemisphere circulation change: A multimodel assessment. J. Geophys. Res., 115, D00M07, https://doi.org/ 10.1029/2010JD014271.

Swart, N. C., and J. C. Fyfe, 2013: The influence of recent Antarctic ice sheet retreat on simulated sea ice area trends. Geophys. Res. Lett., 40, 4328-4332, https://doi.org/10.1002/grl.50820.

Turner, J., and Coauthors, 2009: Non-annular atmospheric circulation change induced by stratospheric ozone depletion and its role in the recent increase of Antarctic sea ice extent. Geophys. Res. Lett., 36, L08502, https://doi.org/10.1029/ 2009GL037524.

—, T. Phillips, J. S. Hosking, G. J. Marshall, and A. Orr, 2013: The Amundsen Sea Low. Int. J. Climatol., 33, 1818-1829, https://doi.org/10.1002/joc.3558.

J. S. Hosking, G. J. Marshall, T. Phillips, and T. J. Bracegirdle, 2016: Antarctic sea ice increase consistent with intrinsic variability of the Amundsen Sea Low. Climate Dyn., 46, 2391-2402, https://doi.org/10.1007/s00382-015-2708-9.

Yu, L., S. Zhong, J. A. Winkler, M. Zhou, D. H. Lenschow, B. Li, X. Wang, and Q. Yang, 2017: Possible connections of the opposite trends in Arctic and Antarctic sea-ice cover. Sci. Rep., 7, 45804, https://doi.org/10.1038/srep45804. 